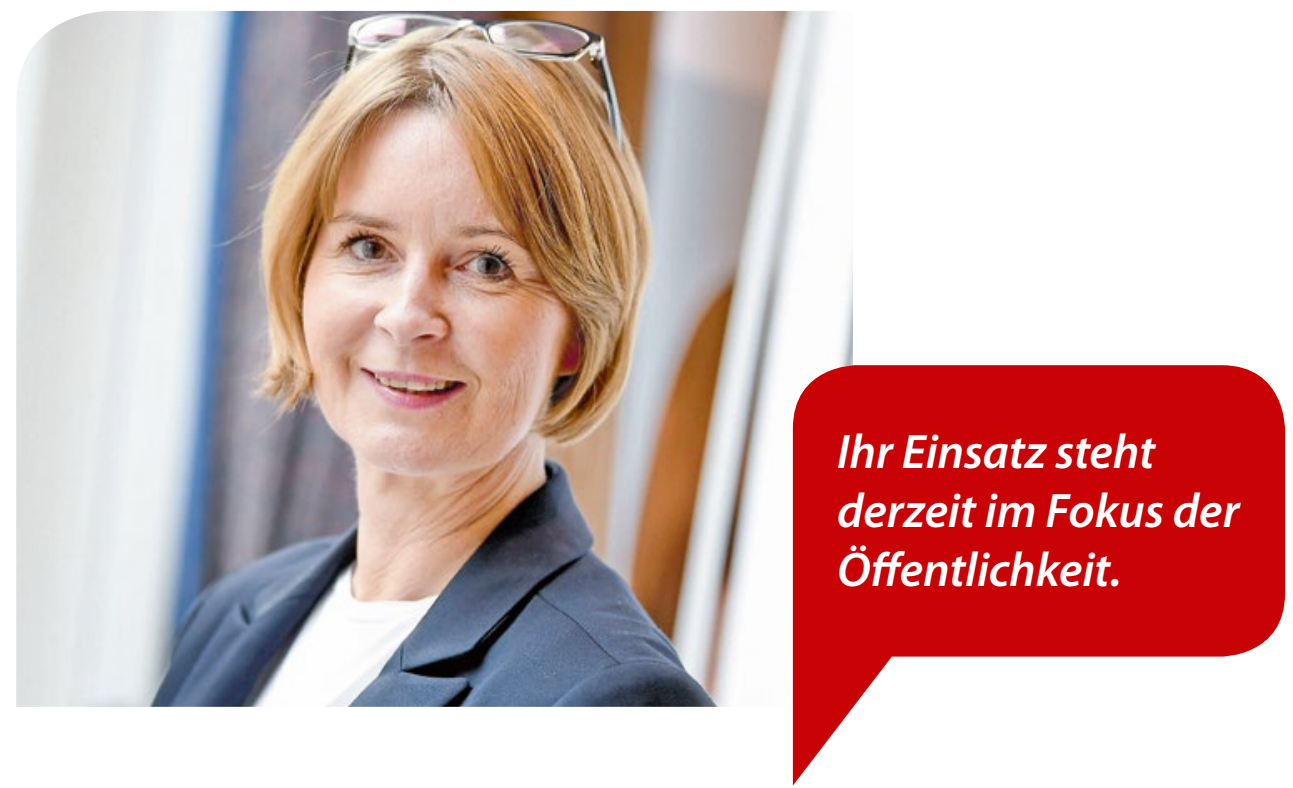

IM MITTELPUNKT Eigentlich könnte man ja denken, dass die medizinische Forschung aktuell im Zentrum der gesellschaftlichen Aufmerksamkeit stehen müsste. Denn haben wir nicht alle ein großes Interesse an einem wirksamen Medikament oder einem Impfstoff gegen Covid-19? Etwas also, das uns veranlasst, der Pharmaindustrie und den Forschenden permanent über die Schulter zu schauen und zur Eile zu drängen. Mein Eindruck ist, dass es vielmehr Ihre Arbeit in den Alten- und Pflegeheimen ist, die die Nachrichten dominiert. Der Einsatz, den Sie leisten, in dem Sie für Ihre Bewohner und Patienten gerade in Corona Zeiten da sind, erweitert unser aller Bewusstsein für das, was für Sie Alltag ist (Seite 43).

GUTE WÜNSCHE Es ist zugegeben schon ein paar Tage her - aber zum Internationalen Tag der Pflegenden haben wir viele gute Wünsche in zahlreichen Video-Botschaften für Sie eingefangen. Wenn Sie es noch nicht gesehen haben, schauen Sie sich das Video gerne an - beispielsweise auf unserer Facebook Seite.

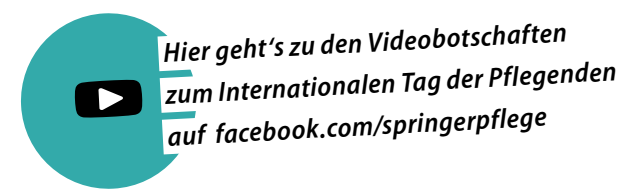

PRAXIS ANLeITEN Zusätzlich zu unseren beiden Fernfortbildungen in dieser Ausgabe haben wir auf springerpflege.de für alle ein kostenfreies PflegeKolleg-Modul zum Lernen und Punkte sammeln bereitgestellt: „Praxisanleitung heute“ - Schauen Sie doch mal rein!

Ihre

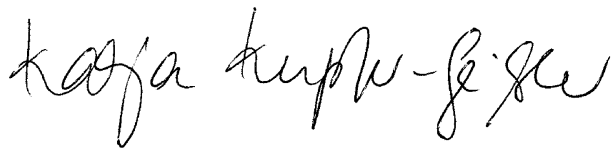

Katja Kupfer-Geißler Chefredakteurin

f katja.kupfer-geissler@springer.com/facebook.com/springerpflege

\section{睡 HAUPTSTADTKONGRESS}

Wegen der COVID-19-Pandemie findet der vom 17. bis 19. Juni 2020 geplante Hauptstadtkongress Medizin und Gesundheit als Präsenzveranstaltung leider nicht statt. Aber Sie müssen nicht ganz auf den Hauptstadtkongress verzichten: Es wird ein neues, digitales Format geben ein „Hauptstadtkongress Spezial 2020".

Start dafür ist eine Kick-off-Veranstaltung am 17. Juni 2020, also an dem Tag, an dem die reguläre Eröffnung des Hauptstadtkongresses 2020 stattgefunden hätte. Seien Sie gespannt!

\section{hauptstadtkongress.de}

